\title{
Endosonography-guided hepatogastrostomy post-percutaneous biliary drainage in collaboration with interventional radiology
}

Endoscopic ultrasonography-guided hepatogastrostomy (EUS-HGS) is an effective endoscopic modality for biliary drainage in the setting of concomitant gastric outlet obstruction [1,2]. EUSHGS however requires a dilated biliary system for technical success. This case report describes the first conversion of a percutaneous transhepatic biliary drain (PTBD) into an HGS in a non-dilated biliary system using EUS and interventional radiology techniques.

A 43-year-old man underwent hepatic resection for metastatic colon cancer with full surgical transection of the com-

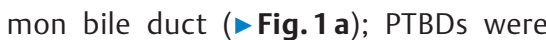
placed. Definitive stable drainage was needed to start adjuvant chemotherapy. Therefore, a decision was taken to perform HGS.

Under EUS guidance, a non-dilated left intrahepatic bile duct was punctured with a 19-gauge needle but, given the small ductal caliber, wire passage was not possible. Two occlusive balloons were inserted via the PTBD, with one central and one peripheral to the puncture target ( Video 1). Saline was infused between the balloons, dilating the isolated duct segment. This allowed passage of a 0.035-inch guidewire ( Fig. $1 \mathbf{b}$ ); however, the wire traveled peripherally in the bile ducts, but was then successfully grasped with a snare and pulled out of the PTBD track. With control of both ends of the wire achieved, the HGS tract was easily dilated to $6 \mathrm{~mm}$ with a balloon inserted through the PTBD. During tract dilation, a $10 \times 80-\mathrm{mm}$ partially covered self-expandable metal stent was simultaneously loaded through the endoscope and was advanced through the HGS tract immediately following deflation of the balloon, thereby minimizing the time between dilation and stent insertion and reducing leakage of bile. The stent was deployed, resulting in excellent drainage ( Fig.2). The patient was discharged
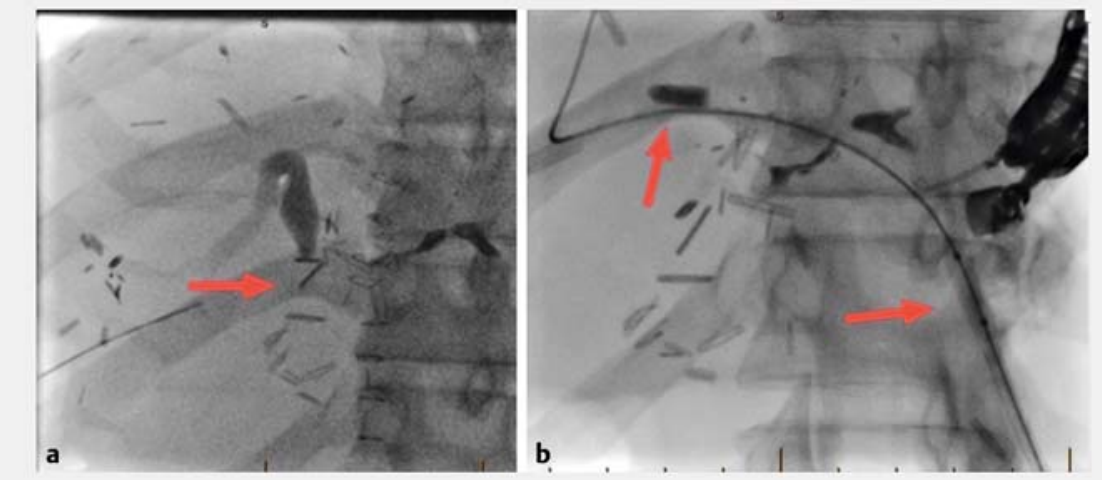

- Fig. 1 Radiographic views showing: a complete cut-off of the bile duct due to a surgical clip; b endoscopic ultrasonography-guided bile duct puncture following dilation of the duct with occlusion balloons and saline infusion.

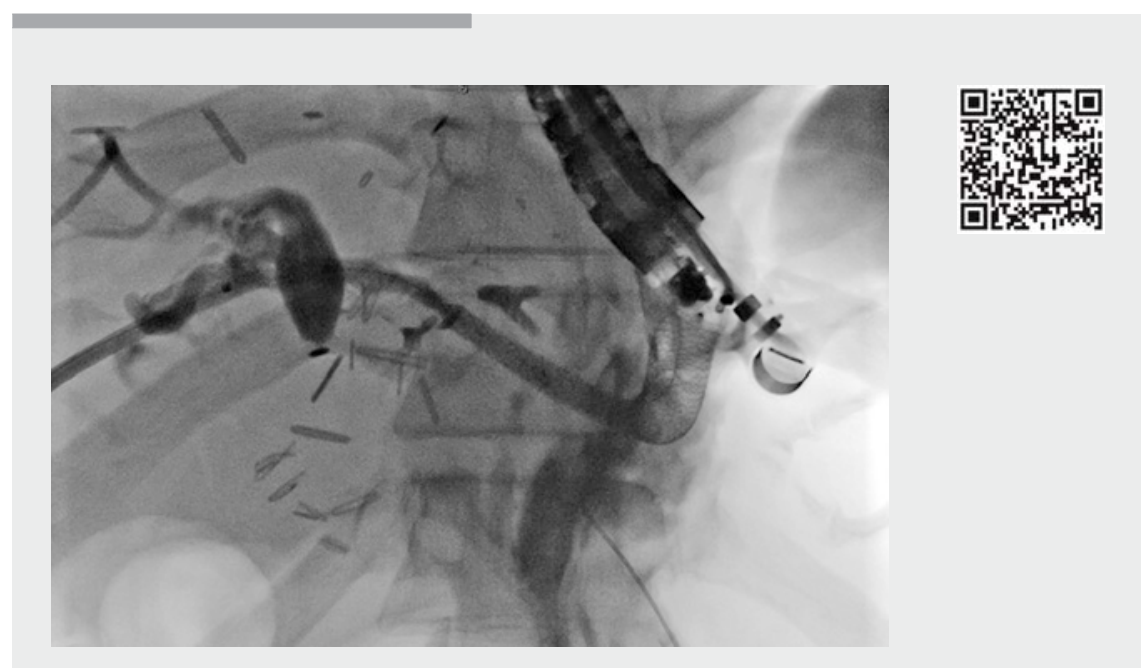

$\checkmark$ Video 1 Successful conversion of a percutaneous biliary drain into a hepatogastrostomy under endoscopic ultrasonography and interventional radiology guidance.

4 days later after normalization of his bilirubin and removal of the PTBD.

We report the first successful conversion of a PTBD to an HGS using EUS and interventional radiology techniques in a nondilated biliary system. This multidisciplinary approach may enhance the safety of HGS.

Endoscopy_UCTN_Code_TTT_1AS_2AD

\section{Competing interests}

Yen-I Chen is a consultant for Boston Scientific; David Valenti has previously been a speaker for Boston Scientific and Cook Medical; and Alan Barkun has served as a consultant for and received funds from Cook Inc., Pendopharm Inc., and Olympus (also research support and advisory committee). All other authors having no relevant conflicts of interest. 

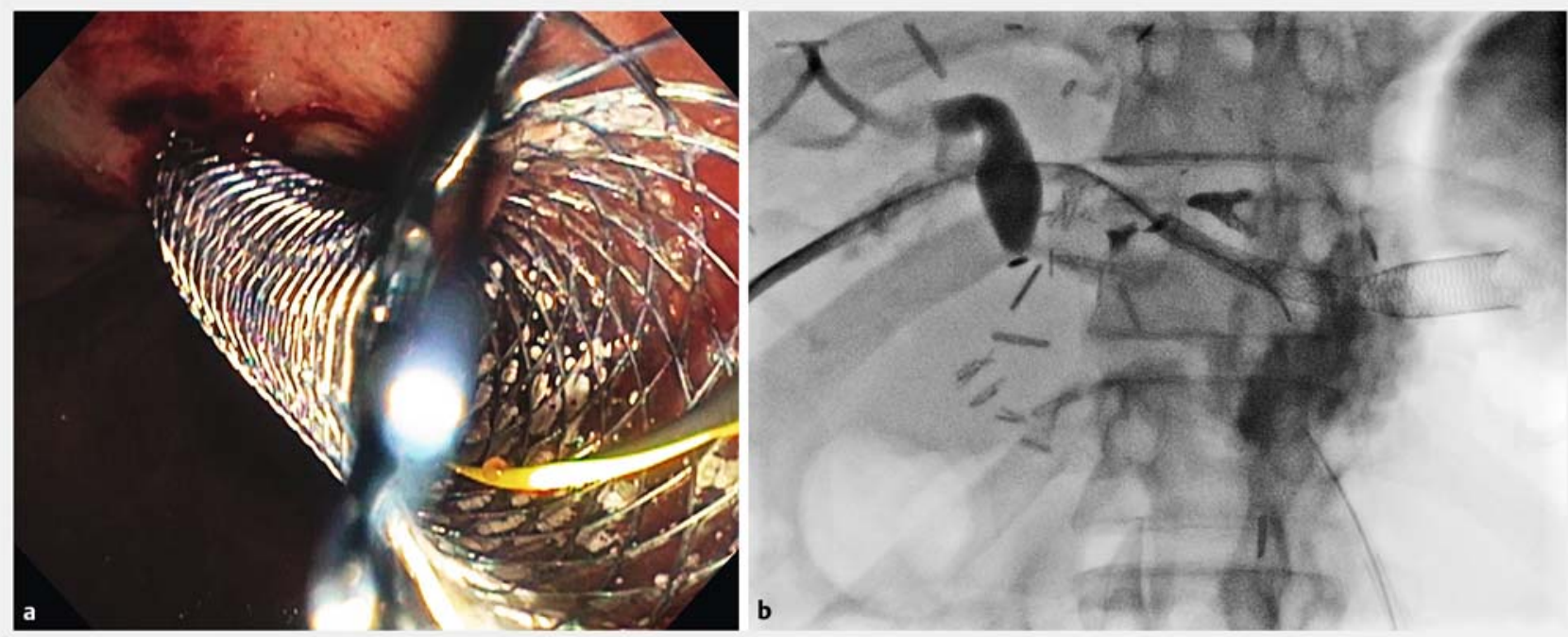

Fig. 2 A partially covered self-expanding metal stent was successfully deployed with excellent positioning to form the hepatogastrostomy, as shown on: a endoscopic view; b fluoroscopic view.

The authors

Ahmad Hashim ${ }^{1}$, Yen-I Chen', David Valenti ${ }^{2}$, Peter Metrakos ${ }^{3}$, Sheryl White ${ }^{1}$, Alan Barkun ${ }^{1}$, Ali Bessissow ${ }^{2}$

1 Division of Gastroenterology and Hepatology, McGill University Health Center, Montréal, Québec, Canada

2 Division of Interventional Radiology, McGill University Health Center, Montréal, Québec, Canada

3 Department of Surgery, McGill University Health Center, Montréal, Québec, Canada

\section{Corresponding author}

\section{Yen-I Chen, MD}

Division of Gastroenterology and Hepatology, McGill University Health Centre, 1001 Decarie Blvd, Montréal, Québec, H4A 3)1, Canada

yen-i.chen@mail.mcgill.ca

\section{References}

[1] Khashab MA, Messallam AA, Penas I et al. International multicenter comparative trial of transluminal EUS-guided biliary drainage via hepatogastrostomy vs. choledochoduodenostomy approaches. Endosc Int Open 2016; 4: E175-E181

[2] Uemura RS, Khan MA, Otoch JP et al. EUSguided choledochoduodenostomy versus hepaticogastrostomy: a systematic review and meta-analysis. J Clin Gastroenterol 2018; 52: $123-130$

\section{Bibliography}

DOI https://doi.org/10.1055/s-0044-101252

Published online: 16.2.2018

Endoscopy 2018; 50: E115-E116

(c) Georg Thieme Verlag KG

Stuttgart · New York

ISSN 0013-726X

\section{ENDOSCOPY E-VIDEOS}

https://eref.thieme.de/e-videos

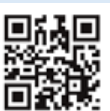

Endoscopy E-Videos is a free access online section, reporting on interesting cases and new techniques in gastroenterological endoscopy. All papers include a high quality video and all contributions are freely accessible online.

This section has its own submission website at

https://mc.manuscriptcentral.com/e-videos 